\title{
Sweat Gland Function in Cystic Fibrosis*
}

\author{
Gary W. Cage, † Richard L. Dobson, and Robert Waller \\ (From the Division of Dermatology, University of Oregon Medical School, Portland, Ore., \\ and the Dermatology Branch, National Cancer Institute and the National Institute \\ of Arthritis and Metabolic Diseases, Bethesda, Md.)
}

In a normal man the sodium concentration of sweat can range from 20 to over $100 \mathrm{mEq}$ per L, depending upon the sweat rate (1). In normal children, the sweat sodium concentration is rarely greater than $60 \mathrm{mEq}$ per $\mathrm{L}$. In fact, a concentration above $70 \mathrm{mEq}$ per $\mathrm{L}$ in a child is generally diagnostic of cystic fibrosis (CF) if adrenal insufficiency can be ruled out (2).

Based on an analysis of the rate of sodium excretion at various sweat rates in adults, evidence (1) has been presented that the sodium concentration of the fluid elaborated by the eccrine secretory coil (secretory fluid) is approximately isotonic to plasma. Hypotonic sweat is produced by reabsorption of sodium in excess of water by the eccrine sweat duct.

In this paper the sweat sodium concentration and rate of sodium excretion as functions of sweat rate have been studied in normal children and adults and in children and adults with CF to determine the reasons for the differences in sweat sodium concentrations in normal adults as compared to normal children, and to localize the site of the defect in the sweat gland in CF, i.e., whether the higher sodium concentration is a result of an abnormality of secretion by the coil or reabsorption in the duct.

\section{Methods}

The normal adults were the six subjects previously reported (1) plus ten other men aged 19 to 23 . The

* Submitted for publication August 18, 1965 ; accepted May 23, 1966.

This study was supported by the following: U. S. Army Research and Development Command, Office of the Surgeon General, contracts DA-49-193-MD 2176 and 2184, and National Institutes of Health grant AM05655 and training grant 5-TI-AM-5300-4.

Presented in part to the Research Conference on Pathogenesis of Cystic Fibrosis of the Pancreas, September 1964, Bethesda, Md.

† Address requests for reprints to Dr. Gary W. Cage, Dermatology Branch, National Cancer Institute, Bethesda, Md. 20014. normal children were two 9-year-old boys, two 11-yearold boys, and two eight-year-old girls. The children with CF were four boys, aged $4,8,8$, and 9 , and one 7 year-old girl. The adults with CF were three women, aged 20,21 , and 26 , and one 17-year-old man.

Eccrine sweat was collected from the foreheads of all groups and analyzed by the method previously reported (1), except : 1) From all children, the sweat was collected on filter papers $2.4 \mathrm{~cm}$ in diameter within collection chambers $2.5 \mathrm{~cm}$ in diameter. 2) The children could not be encouraged to exercise as vigorously as the adults. 3) The adults with CF were limited in their ability to exercise vigorously by significant pulmonary disease. The children with CF did not appear to be limited in their ability to exercise by their basic disease. 4) The total experimental duration for Subject A-7 was 100 minutes. For all other subjects the total duration of the experimental stress was less than 70 minutes.

The longest duration of sampling was 10 minutes, but most samples were taken in periods of less than 5 minutes.

At some time during the experiment each child and normal adult were subjected to what was considered by subjective impression of the experimentors as a maximally tolerated stress of heat, humidity, and exercise.

\section{Results}

In Figure 1 the sweat sodium concentration is plotted vs. sweat rate for all four groups. The ranges of sweat rates produced by the children with $\mathrm{CF}$ and normal children are comparable. Much higher sweat rates were produced by the normal adults. The sweat rates from the adults with $\mathrm{CF}$ cannot be compared to the other groups because of the lesser stress used.

All but two of the values from normal children fall in the sweat rate range from 0 to $20 \mathrm{ml}$ per minute per square meter. In this sweat rate range, 63 points were obtained from the six normal children and 67 from the 16 normal adults. The average sodium concentration in this range was $41(\mathrm{SD} \pm 24.0) \mathrm{mEq}$ per $\mathrm{L}$ for the adults and 32 $(\mathrm{SD} \pm 14.4)$ for the normal children. The difference of these means is not significant $(0.5>$ $\mathrm{p}>0.4$ ) by Student's $t$ test. In this sweat rate 


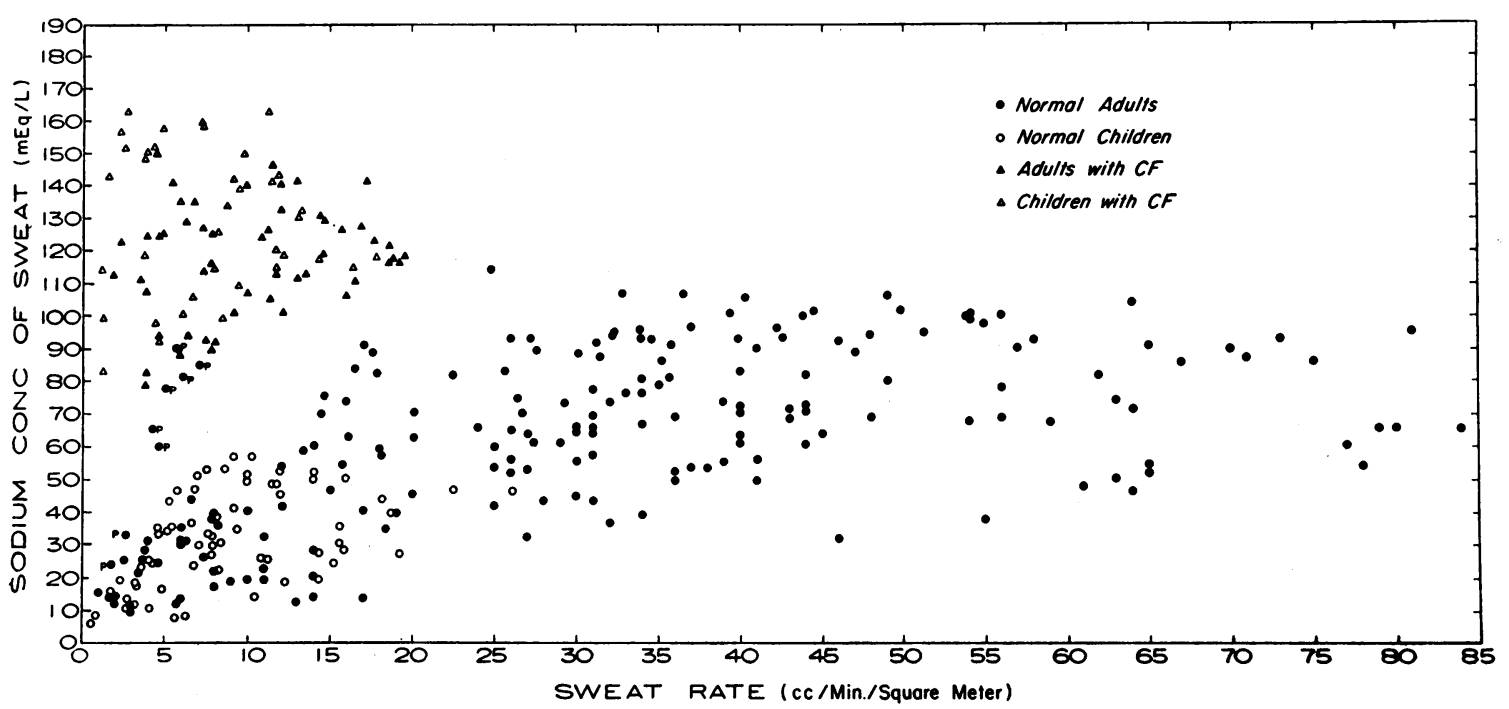

Fig. 1. Plots of sweat sodium concentration vs. SWEat Rates for NORMal adults (16) AND CHILdReN (6), AND ADUlts (4) AND CHILdREN with CF (5). Points marked " $p$ " are from a single normal adult $(A-1)$. CF = cystic fibrosis.

range, which includes almost all of the points from all subjects except normal adults, the points from the children and adults with CF clearly constitute a different population. The only points that over- lap between the normal subjects and patients with CF were from a single adult (Subject A-1, marked $\mathrm{p}$ in Figure 1). Sodium concentrations above 70 $\mathrm{mEq}$ per $\mathrm{L}$, the diagnostic range for $\mathrm{CF}$ in chil-

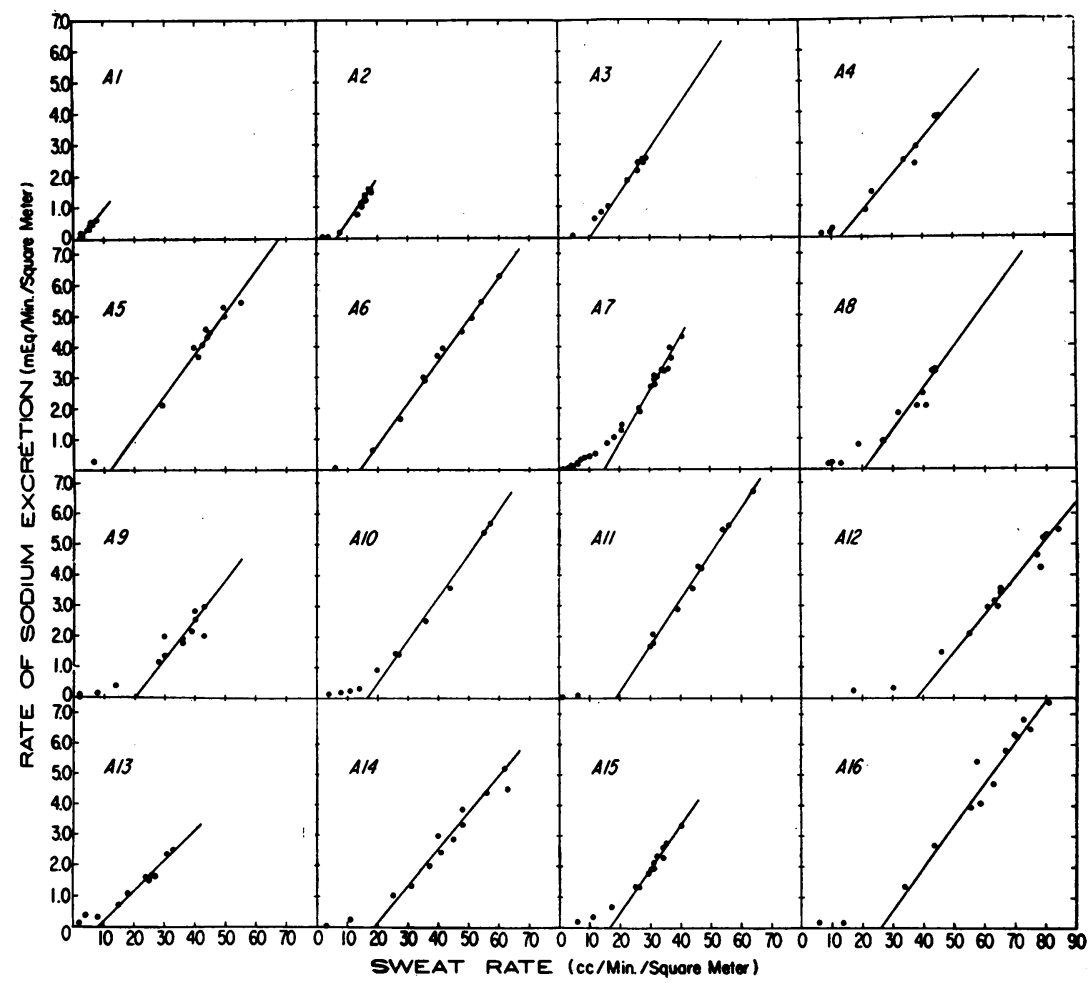

Fig. 2. Rate of SODIUM EXCRetion vs. SWEAT Rate FOR NORMal ADUlts. 


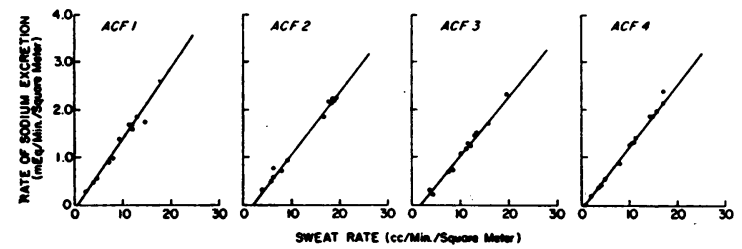

Fig. 3. RAte of SOdium EXCREtion vs. SWeat Rate for ADULTS WITH CF.

dren, were produced by all but two of the normal adults, generally at much higher sweat rates.

Figure 2 shows the plots of the rate of sodium excretion vs. sweat rate for the normal adults. Figure 3 shows the plots of rate of sodium excretion vs. sweat rate for the adults with cystic fibrosis. Table I lists the derived values for the sodium concentrations of the secretory fluid obtained from the slopes of the curves in Figures 2 and 3. Table II gives the calculated maximal free water clearance by the duct obtained by extrapolation of these curves to the $x$ intercept (1). The mean sodium concentration of the secretory fluid does not differ between the two groups. In adults with CF the mean maximal free water clearance is significantly reduced.

In Figure 4 the plots of rate of sodium excretion vs. sweat rate are given for the children with $\mathrm{CF}$. The calculated sodium concentration of the

TABLE I

Sodium concentrations of secretory fluid*

\begin{tabular}{|c|c|c|c|}
\hline \multicolumn{2}{|c|}{ Normal adults } & \multicolumn{2}{|c|}{ Adults with CF } \\
\hline Subject & & Patient & \\
\hline $\begin{array}{l}\text { A-1 } \\
\text { A-2 } \\
\text { A-3 } \\
\text { A-4 } \\
\text { A-5 } \\
\text { A-6 } \\
\text { A-7 } \\
\text { A-8 } \\
\text { A-9 } \\
\text { A-10 } \\
\text { A-11 } \\
\text { A-12 } \\
\text { A-13 } \\
\text { A-14 } \\
\text { A-15 } \\
\text { A-16 }\end{array}$ & $\begin{array}{l}m E q / L \\
122 \\
172 \\
145 \\
117 \\
137 \\
134 \\
172 \\
134 \\
129 \\
140 \\
150 \\
122 \\
100 \\
116 \\
142 \\
139\end{array}$ & $\begin{array}{l}\text { ACF-1 } \\
\text { ACF-2 } \\
\text { ACF-3 } \\
\text { ACF-4 }\end{array}$ & $\begin{array}{l}m E q / L \\
150 \\
131 \\
126 \\
132\end{array}$ \\
\hline $\begin{array}{l}\text { Mean } \\
\text { SD }\end{array}$ & $\begin{array}{r}135.7 \\
19.0\end{array}$ & $\mathrm{p}>.99$ & $\begin{array}{r}134.8 \\
10.5\end{array}$ \\
\hline
\end{tabular}

* Derived values for the sodium concentrations of the secretory fluid for normal adults and adults with cystic fibrosis (CF)
TABLE II

Maximal free water clearance*

\begin{tabular}{|c|c|c|c|}
\hline \multicolumn{2}{|c|}{ Normal adults } & \multicolumn{2}{|c|}{ Adults with CF } \\
\hline \multicolumn{2}{|l|}{ Subject } & \multicolumn{2}{|l|}{ Patient } \\
\hline & $m l / m i n / m^{2}$ & & $\mathrm{ml} / \mathrm{min} / \mathrm{m}^{2}$ \\
\hline A-1 & 1.9 & ACF-1 & 0.76 \\
\hline A-2 & 8.6 & $\mathrm{ACF}-2$ & 1.89 \\
\hline A-3 & 10.0 & $A C F-3$ & 1.67 \\
\hline A-4 & 13.5 & ACF-4 & 0.52 \\
\hline A-5 & 12.3 & & \\
\hline A-6 & 13.8 & & \\
\hline A-7 & 15.2 & & \\
\hline A-8 & 21.2 & & \\
\hline A-9 & 20.3 & & \\
\hline A-10 & 16.6 & & \\
\hline A-11 & 18.9 & & \\
\hline A-12 & 38.0 & & \\
\hline A-13 & 8.5 & & \\
\hline A-14 & 18.6 & & \\
\hline A-15 & 16.3 & & \\
\hline A-16 & 26.1 & & \\
\hline Mean & 16.24 & & 1.20 . \\
\hline $\mathrm{SD}$ & 8.23 & $\mathrm{p}<0.005$ & 0.67 \\
\hline
\end{tabular}

* Derived values for the maximal free water clearance for normal adults and adults with cystic fibrosis.

secretory fluid (Table III) does not differ either from the normal adults $(p>0.2)$ or the adults with CF $(p>0.3)$. The maximal free water clearance (Table III) does not differ significantly from that of the adults with CF ( $p>0.05)$ but is significantly less than that of normal adults $(\mathrm{p}<$ 0.001 ).

Figure 5 shows plots of rate of sodium excretion vs. sweat rate for the group of normal children. At their highest sweat rates it is clear for several

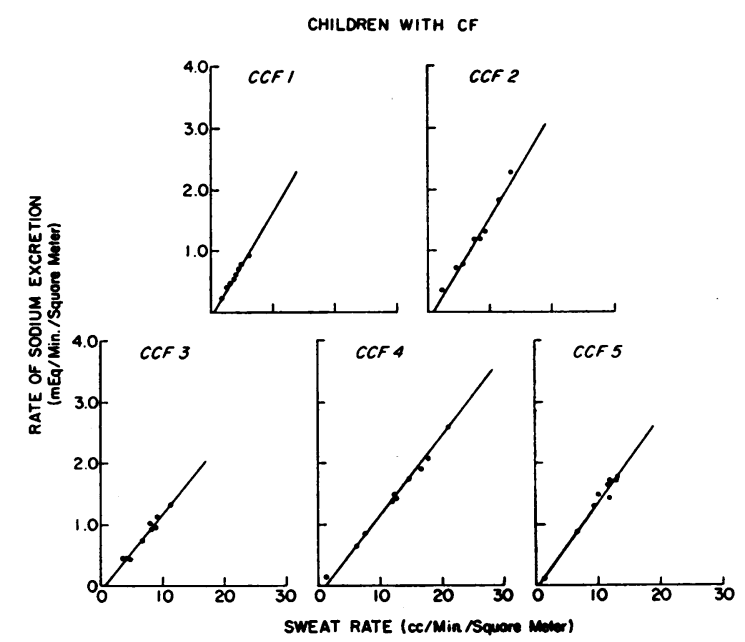

Fig. 4. RATE OF SODIUM EXCRETION vS. SWEAT RATE FOR CHILDREN WITH CF. 
TABLE III

Derived values for sodium concentration of secretory fuid from children with $C F$

\begin{tabular}{ccc}
\hline \hline Patient & $\begin{array}{c}\text { Sodium con- } \\
\text { centration of } \\
\text { secretory fluid }\end{array}$ & $\begin{array}{c}\text { Maximal free } \\
\text { water clearance }\end{array}$ \\
\hline & $m E q / L$ & $m l / m i n / m^{2}$ \\
CCF-1 & 193 & 0.62 \\
CCF-2 & 166 & 0.87 \\
CCF-3 & 126 & 0.78 \\
CCF-4 & 128 & 0.11 \\
CCF-5 & 139 & 0.01 \\
Mean & 150.4 & 0.48 \\
SD & 28.6 & 0.40 \\
\hline
\end{tabular}

of these subjects that the slope of the curve is continuing to increase and a linear portion is never reached.

\section{Discussion}

In this study the stress of heat, humidity, and exercise varied somewhat from individual to individual. In an acute experiment this should produce no appreciable error, since exercise and heat stress probably influence sweat sodium concentration by their effects on sweat rate (1).

The major source of error in the determination of both the sodium concentration of sweat and the sweat rate is probably from evaporation of water from the filter papers. This was reduced as much as possible by the lapse of less than 12 seconds from opening the chamber to enclosing the filter paper in the weighing bottle. Recovery experiments (1) had shown that this error was less than about $5 \%$.

Our studies indicate that the forehead sweat sodium concentration of normal children does not

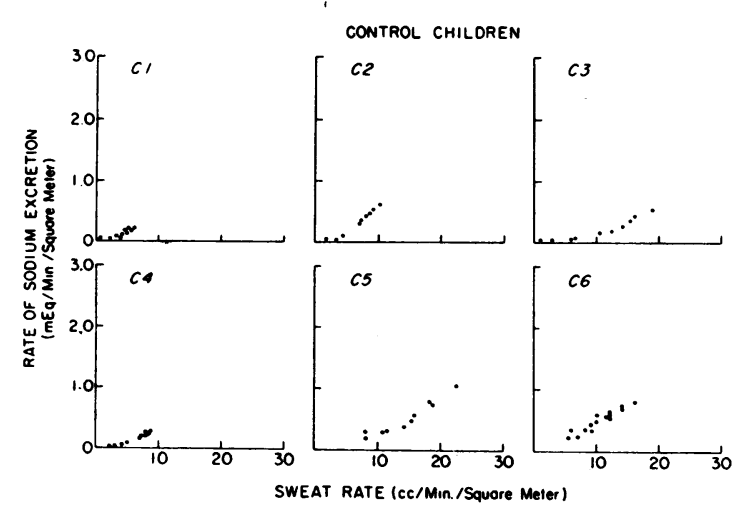

Fig. 5. Plots of Rate of SODIUM Excretion vs. SWEat RATE FOR NORMAL CHILDREN. differ from adults provided the sweat rates are equivalent. The higher sweat sodium concentrations produced in adults were not obtained in children primarily because the higher sweat rates were not obtained and, conceivably, cannot be produced. These data are in conflict with those of Lobeck and Heubner (3), who reported that the sweat sodium concentrations were generally higher in adults than in children at equivalent sweat rates. These conclusions, however, were based on sweat collected from the forearm that had been induced by pilocarpine iontophoresis, with much longer collection periods.

The sweat rates for our children with $\mathrm{CF}$ and normal children were comparable, but the former invariably had a higher sweat sodium concentration.

From Figure 1 several values from the patients with $C F$ appear to be substantially higher than the upper limit of serum sodium concentration. With normal serum protein concentrations, approximately a $7 \%$ correction is necessary to increase sodium concentration of serum to content per liter of water (4), whereas for sweat this correction is less than $1 \%$ (5). Making these corrections, and with an experimental error of approximately $5 \%$, these values probably do not exceed the upper limits of serum sodium concentration of $143 \mathrm{mEq}$ per $\mathrm{L}$ of serum.

One normal adult produced sweat sodium concentrations that overlapped with values from the adults with CF (Figure 1). All but two of the adults did have some samples of sweat with sodium concentrations greater than $70 \mathrm{mEq}$ per $\mathrm{L}$, but only at higher sweat rates. None of the values from normal children overlapped with values from adults or children with $\mathrm{CF}$ at the sweat rates produced.

It is suggested that normal adults with high sweat sodium concentrations above $70 \mathrm{mEq}$ per $\mathrm{L}$ might be distinguishable from patients with $\mathrm{CF}$ if the sodium concentrations are correlated with the sweat rates.

The mean of the calculated sodium concentrations of the secretory fluid of the adults with $\mathrm{CF}$ does not differ significantly from that of the control group of normal adults. Neither does the mean of the calculated sodium concentrations of the secretory fluid from the children with CF differ from those of either of these groups. 
The determination of the sodium concentration of the secretory fluid depends upon the assumption that if the transfer maximum for sodium reabsorption by the duct is exceeded, there is a linear relationship between rate of sodium excretion and sweat rate (6). The points that we obtained from normal children (Figure 5) do not clearly become linear. These points fall perhaps on the initial nonlinear portion of the curve before the transfer maximum for sodium reabsorption is exceeded. Although some of these curves may possibly become linear at higher sweat rates, we did not feel it safe to subject these children to greater stress and therefore do not know whether significantly higher sweat rates were producible. However, since the sodium concentrations of normal children and adults are comparable at equivalent rates and the points for rate of sodium excretion lie in the same general area of the initial nonlinear portion of the curves for normal adults, there is no reason to presume that the sodium concentrations of the secretory fluid and free water clearance are different in normal children and adults.

In contrast with normal children, plots of the rate of sodium excretion vs. sweat rate for children with $\mathrm{CF}$ become linear at low sweat rates. Therefore it is possible to calculate the sodium concentration of the secretory fluid and the maximal free water clearance.

The values for the sodium concentration of the secretory fluid show considerable variation within each group. Added to the physiological variation, probably of the same order of magnitude as that of serum sodium concentration, is the experimental error resulting from an indirect estimate. As previously noted (1), a systematic error tending to underestimate the true value may arise if the curves approach linearity asymptotically instead of becoming essentially linear at a point; the value from a patient with $\mathrm{CF}$ with a lower maximal free water clearance might be expected to approximate the true value more closely than the normal subject with a higher maximal free water clearance. The potential error of evaporation from samples contributes to variation but should be operative to about the same degree on all samples and not interfere substantially with comparisons. Random error resulting from incomplete removal of sweat from the skin and errors in weighing, timing of the periods, dilution of the samples, and in the deter- minations themselves contribute to the considerable variation among individual estimates in each group. Because of this variation and the small size of the populations studied, neither the means nor the spread of individual values should be interpreted as precise limits for the true value of the sodium concentration of the secretory fluid. Granted this variation in estimate, we could find no statistical evidence for differences in the mean values between the CF group and control group. The true means might differ by a few milliequivalents per liter and not be detected by the present method, except perhaps by studying much larger populations. Even if differences do exist, the present data suggest that they are of insufficient magnitude to explain the difference in sweat sodium concentration between the control group and the patients with $\mathrm{CF}$.

The finding of no differences in the mean concentrations of sodium in the secretory fluids in normal subjects and patients with $\mathrm{CF}$ is at variance with the results obtained by Gibson and Di Sant' Agnese (7). These investigators concluded that the sum of sodium and potassium concentrations of the secretory fluid was greater in children with $\mathrm{CF}$ than in normal children and adults. Their conclusions were based on sweat that was obtained after pharmacological stimulation, primarily from the forearm. Their values for children with $\mathrm{CF}$ are roughly comparable to ours if a potassium concentration approximately equal to serum potassium is assumed for the secretory fluid. But, as previously noted (1), their values for normal adults are much lower. Our results are in agreement with those of Slegers (8), who, by use of a cryoscopic method, could find no difference in the freezing points of the secretory fluid of patients with $\mathrm{CF}$ and normal controls.

The markedly lower maximal free water clearance in the patients with $\mathrm{CF}$ localizes a defect in the duct. This could be due to 1 ) inability to reabsorb sodium in the duct either because of a primary defect or secondary to interference with reabsorption by a substance secreted by the coil, or 2) normal or even increased sodium reabsorption in the duct, but the duct could be unable to restrict the passive reabsorption of water from the lumen. Our data do not allow us to choose between these two possibilities. 


\section{Summary}

The relationship of sodium concentration and rate of sodium excretion to sweat rate was determined on thermal sweat collected from the foreheads of normal children and adults, and children and adults with cystic fibrosis (CF).

At equivalent sweat rates the sweat sodium concentrations of normal children and adults do not differ. Sodium concentrations greater than 70 $\mathrm{mEq}$ per $\mathrm{L}$, which can be produced in normal adults by high sweat rates, were not obtained from children because high sweat rates were not produced or producible.

Sweat sodium concentrations from children and adults with $\mathrm{CF}$ were greater than $70 \mathrm{mEq}$ per L even at low sweat rates and were consistently separable from values from the normal children. Some values from normal adults did overlap with values from those patients with $\mathrm{CF}$ but generally only at much higher sweat rates.

The sodium concentration of the secretory fluid and the maximal free water clearance could not be determined for normal children by analysis of the relationship of the rate of sodium secretion to the rate of sweat formation because the transfer maximum for sodium reabsorption was not exceeded at the sweat rates produced.

The mean sodium concentration of the secretory fluid from both adults and children with CF could not be shown to differ from that of normal adults. The maximal free water clearance is significantly less in both adults and children with CF com- pared with normal adults. This indicates that in $\mathrm{CF}$ there is a defect in the duct of the sweat gland.

\section{Acknowledgments}

We wish to thank Dr. Paul di Sant'Agnese of the National Institute of Arthritis and Metabolic Diseases, who allowed us to study adult patients with cystic fibrosis under his care and Dr. Robert Cambell of the University of Oregon and the Cystic Fibrosis Foundation of Portland, who made it possible for us to study the children with cystic fibrosis.

\section{References}

1. Cage, G. W., and R. L. Dobson. Sodium secretion and reabsorption in the human eccrine sweat gland. J. clin. Invest. 1965, 44, 1270.

2. Shwachman, H. The sweat test. Pediatrics 1962, 30, 167.

3. Lobeck, C. C., and D. Huebner. Effect of age, sex, and cystic fibrosis on the sodium and potassium content of human sweat. Pediatrics 1962, 30, 172.

4. Eisenman, A. J., L. B. Mackenzie, and J. P. Peters. Protein and water of serum and cells of human blood, with a note on the measurement of red blood cell volume. J. biol. Chem. 1936, 116, 33.

5. Kuno, Y. Human Perspiration. Springfield, Charles C Thomas, 1956, p. 223.

6. Schwartz, I. L., and J. H. Thaysen. Excretion of sodium and potassium in human sweat. J. clin. Invest. 1956, 35, 114.

7. Gibson, L. E., and P. A. di Sant'Agnese. Studies of salt excretion in sweat. Relationships between rate, conductivity, and electrolyte composition of sweat from patients with cystic fibrosis and from control subjects. J. Pediat. 1963, 62, 855.

8. Slegers, J. F. G. The mechanism of eccrine sweatgland function in normal subjects and in patients with mucoviscoidosis. Dermatologica (Basel) 1963, 127, 242.

\section{SPECIAL NOTICE TO SUBSCRIBERS}

Post Offices will no longer forward the Journal when you move.

Please notify The Journal of Clinical Investigation, Business Office, 10 Stoughton Street, Boston, Mass. 02118, at once when you have a change of address, and do not omit the Zip Code number. 